\title{
Graded substitution of grains with bakery by-products modulates ruminal fermentation, nutrient degradation, and microbial community composition in vitro
}

\author{
E. Humer, ${ }^{* 1}$ S. Aditya, ${ }^{*} \dagger$ A. Kaltenegger, ${ }^{*}$ F. Klevenhusen, ${ }^{*}$ R. M. Petri, ${ }^{*}$ and Q. Zebeli* \\ *Institute of Animal Nutrition and Functional Plant Compounds, Department for Farm Animals and Veterinary Public Health, \\ University of Veterinary Medicine Vienna, Veterinaerplatz 1,1210 Vienna, Austria \\ †Directorate General of Human Resource for Science, Technology, and Higher Education-Indonesia, 10270 Jakarta, Indonesia
}

\begin{abstract}
A new segment of feed industry based on bakery by-products (BBP) has emerged. Yet, information is lacking regarding the effects of inclusion of BBP in ruminant diets on ruminal fermentation and microbiota. Therefore, the aim of this study was to evaluate the effect of the gradual replacement of grains by BBP on ruminal fermentation, nutrient degradation, and microbial community composition using the rumensimulation technique. All diets consisted of hay and concentrate mixture with a ratio of 42:58 (dry matter basis), but differed in the concentrate composition with either $45 \%$ cereal grains or BBP, whereby 15,30 , or $45 \%$ of BBP were used in place of cereal grains. The inclusion of increasing levels of BBP in the diet linearly enhanced ruminal degradation of starch from $84 \%$ (control) to $96 \%$ (45\% BBP), while decreasing degradation of crude protein and fiber. The formation of methane was lowered in the $45 \%$ BBP diet compared with all other diets. Whereas the ammonia concentration was similar in the control and $15 \% \mathrm{BBP}$, a significant decrease was found in $30 \% \mathrm{BBP}(-23 \%)$ and $45 \% \mathrm{BBP}$ $(-33 \%)$. Also, BBP feeding shifted fermentation profile toward propionate at the expense of acetate. Moreover, isobutyrate linearly decreased with increasing BBP inclusion. Bacterial 16S rRNA Illumina MiSeq (Microsynth AG, Balach, Switzerland) sequencing revealed a decreased microbial diversity for the $45 \%$ BBP diet. Furthermore, the replacement of cereal grains with BBP went along with an increased abundance of the genera Prevotella, Roseburia, and Megasphaera, while decreasing Butyrivibrio and several OTU belonging to Ruminococcaceae. In conclusion, the inclusion of BBP at up to $30 \%$ of the dry matter had no detrimental effects on $\mathrm{pH}$, fiber degradability, and microbial diversity,
\end{abstract}

Received October 26, 2017.

Accepted December 20, 2017.

${ }^{1}$ Corresponding author: Elke.Humer@vetmeduni.ac.at and enhanced propionate production. However, a higher replacement level (45\%) impaired ruminal fermentation traits and fiber degradation and is not recommended.

Key words: bakery by-product, cereal grain, nutrient disappearance, ruminal fermentation, ruminal microbiota

\section{INTRODUCTION}

Due to the continuous increase in grain demands, concerns about future food security are rising, which in turn reinforces pressure on livestock systems (Godfray et al., 2010). Although ruminants are able to convert fibrous plant material into high-quality animal products, the high performance levels reached in modern intensive ruminant production systems make it necessary to feed high amounts of energy-rich concentrates (i.e., cereal grains) to ruminants. One strategy to cover the nutrient requirements of high-producing ruminants while reducing the food competition between cattle and humans is the inclusion of energy-rich by-products in the diets. Among the possible by-products fed to ruminants, leftovers from bakeries can serve as energetic food, due to their high concentration of NFC and fat (Arosemena et al., 1995). In many countries, bakery products are frequently delivered to the stores to ensure freshness and those not sold within a day are returned. Although these products are wholesome, their use for human consumption is largely prevented due to consumers' preferences and business policy. Thus, a large volume of bakery by-products (BBP) has become available, resulting in the emergence of a whole new segment of the feed industry (Wing, 1964; Franca et al., 2012).

As BBP is characterized by its high energy content, mainly due to the high concentration of NFC (Arosemena et al., 1995), it shows potential as a substitute for cereal grains in ruminant diets. Although BBP is often fed to farm livestock, including lactating dairy cows, little pertinent research is found in the current 
literature (Champe and Church, 1980). Especially research regarding the effects on microbial community structure is missing, and the only report available in dairy cows was conducted half a century ago (Wing, 1964). In general, starch-rich feed ingredients differ largely in the rate and extent of starch degradability (Humer and Zebeli, 2017). Increasing amounts of degradable starch cause a shift in the fermentation profile toward propionate at the expense of acetate, thereby supporting gluconeogenesis and energy supply to the host (Deckardt et al., 2013). However, excessive starch degradation decreases ruminal $\mathrm{pH}$, which enhances the risk of ruminal fermentation disorders. A decrease in ruminal $\mathrm{pH}$ is associated with negative effects on fibrolytic bacteria, thereby lowering the ruminal fiber degradability (Humer et al., 2017). Thus, a possible increase in the amount of ruminally degradable NFC in the BBP might enhance ruminal starch fermenters at the expense of cellulolytic microbes. Furthermore, the high fat contents typically found in BBP might impair ruminal fibrolytic bacteria when high amounts are included in the diet (Enjalbert et al., 2017). However, the effects of feeding of BBP on the ruminal nutrient degradability, fermentation profile, and microbial community structure have not been investigated so far. With the help of next-generation sequencing techniques, it is possible to gain a deep understanding of rumen bacterial shifts in response to different diets.

Therefore, the aim of this study was to evaluate the effect of the successive replacement of cereal grains by $\mathrm{BBP}$ on ruminal fermentation characteristics, nutrient degradation, and microbial community composition using the rumen-simulation technique (Rusitec).

\section{MATERIALS AND METHODS}

\section{Treatments and Experimental Diets}

Four experimental diets were formulated, all containing $42 \%$ meadow hay and $58 \%$ concentrates (DM basis), with the concentrate mixture differing in its composition among diets (Table 2). The control diet (CON) contained $45 \%$ cereal grains in diet DM. For the second diet $(15 \% \mathrm{BBP})$, one-third of the cereal grains were replaced with BBP, reaching a level of $15 \%$ in total diet DM. The third diet contained 30\% BBP and $15 \%$ cereal grains (30\% BBP), thereby substituting the cereal portion by two-thirds. Finally, a diet in which the native grains were completely replaced by BBP $(45 \% \mathrm{BBP})$ was formulated. The cereal proportion in the first 3 diets consisted of $75 \%$ wheat and $25 \%$ rye, based on the typical composition of the original bakery products. Before use, hay was chopped to about $6 \mathrm{~mm}$ in length (Pulverisette 25/19, Fritsch GmBH, Idar-Obersteinn, Germany), whereas the concentrate ingredients were ground to pass a $2-\mathrm{mm}$ sieve, using the same mill. The BBP used was a mixture of leftover materials collected from Viennese bakeries and supermarkets. The analyzed chemical composition of the individual ingredients (Table 1) was used to formulate the diets.

\section{Experimental Design, Rusitec Procedure, and Sample Collection}

The experiment was based on a completely randomized arrangement, whereby 4 diets were tested in 3 experimental runs with 3 replicates in each run, resulting in 9 independent measurements per treatment. Each run consisted of 12 fermentors and lasted for 10 $\mathrm{d}$, wherein the final $5 \mathrm{~d}$ were used for samplings. For each experimental run, ruminal fluid and solid digesta were obtained from 3 nonlactating rumen-cannulated Holstein cows kept at the Dairy Research Station of the University of Veterinary Medicine Vienna (Pottenstein, Austria). Donor cows were fed with hay and grass silage and were kept according to Austrian guidelines for animal welfare (Federal Ministry of Health, 2004). Prior to inoculation, the ruminal fluid of the cows was mixed and filtered through 4 layers of medical gauze ( 1-mm pore size), whereas the solid digesta was mixed and used unprocessed. Each fermentor was inoculated with $600 \mathrm{~mL}$ of rumen fluid and $100 \mathrm{~mL}$ of artificial saliva. Subsequently, a pair of nylon bags $(120 \times 65$ $\mathrm{mm}, 150 \mu \mathrm{m}$ pore size, Fa. Linker Industrie-Technik GmbH, Kassel, Germany) was added to each fermentor, one filled with $12 \mathrm{~g}$ of $\mathrm{DM}$ of the experimental diet and another bag filled with solid ruminal digesta. The Rusitec apparatus and procedure is explained in detail in a previous study (Khiaosa-Ard et al., 2015), except for a different infusion rate of artificial saliva of $331 \pm$ $16.0 \mathrm{~mL} / \mathrm{d}$.

Daily effluent and fermentation gases of each fermentor were collected in effluent bottles kept in an ice tub and gas-tight bags (TecoBag $8 \mathrm{~L}$, Tesseraux Spezialverpackungen GmbH, Bürstadt, Germany), respectively. On the sampling days, directly before feed bag exchange, fermentor fluid samples were collected using a syringe. Part of the fluid samples was immediately analyzed for daily measurement of fermentation characteristics $(\mathrm{pH}$, redox potential), and additional subsamples were stored in separate tubes at $-20^{\circ} \mathrm{C}$ for analysis of short-chain fatty acids (SCFA) and ammonia. For microbial analysis, additional fluid subsamples were snap frozen in liquid nitrogen and stored at $-80^{\circ} \mathrm{C}$ until DNA extraction. The incubation feed (residue) 
Table 1. Chemical composition and fatty acid profile of diet ingredients (\% of DM unless stated)

\begin{tabular}{|c|c|c|c|c|c|}
\hline Item & Hay & Wheat & Rye & $\mathrm{BBP}^{1}$ & $\mathrm{RSM}^{2}$ \\
\hline $\mathrm{DM}(\%$ of fresh matter) & 92.6 & 86.0 & 86.1 & 92.1 & 87.5 \\
\hline Ash & 8.7 & 1.7 & 1.7 & 3.1 & 7.2 \\
\hline $\mathrm{CP}$ & 15.7 & 12.8 & 9.6 & 12.9 & 37.5 \\
\hline NDF & 61.7 & 11.7 & 15.2 & 6.4 & 24.7 \\
\hline $\mathrm{ADF}$ & 38.9 & 4.3 & 3.6 & 2.2 & 20.7 \\
\hline Ether extract & 2.7 & 2.0 & 1.6 & 12.2 & 4.2 \\
\hline Starch & - & 67.7 & 61.6 & 53.4 & - \\
\hline Sugar & 5.3 & 4.2 & 7.1 & 10.7 & 10.7 \\
\hline $\mathrm{NE}_{\mathrm{L}}(\mathrm{MJ} / \mathrm{kg}$ of $\mathrm{DM})$ & 5.11 & 8.53 & 8.54 & 9.32 & 7.49 \\
\hline Calcium & 0.50 & 0.07 & 0.08 & 0.12 & 0.70 \\
\hline Phosphorus & 0.32 & 0.33 & 0.34 & 0.23 & 1.14 \\
\hline Phytate-phosphorus & - & 0.19 & 0.18 & 0.07 & 0.62 \\
\hline Magnesium & 0.29 & 0.10 & 0.12 & 0.08 & 0.49 \\
\hline Potassium & 2.38 & 0.47 & 0.46 & 0.33 & 1.26 \\
\hline Sodium & 0.059 & 0.014 & 0.014 & 0.647 & 0.077 \\
\hline \multicolumn{6}{|c|}{ Fatty acid ( $\mathrm{g} / \mathrm{kg}$ of fresh matter) } \\
\hline SFA & 6.366 & 6.120 & 10.256 & 25.681 & 6.682 \\
\hline MUFA & 1.279 & 3.367 & 1.938 & 49.881 & 14.398 \\
\hline PUFA & 6.447 & 11.958 & 9.190 & 27.067 & 8.658 \\
\hline UFA:SFA & 1.21 & 2.50 & 1.09 & 3.00 & 3.45 \\
\hline C8:0 & 0.022 & 0.017 & 0.025 & $\mathrm{ND}^{3}$ & 0.023 \\
\hline C10:0 & 0.106 & ND & ND & 0.476 & ND \\
\hline C11:0 & 0.296 & 0.052 & ND & 0.081 & 0.110 \\
\hline C12:0 & 0.084 & 0.051 & 0.054 & 0.923 & 0.041 \\
\hline C13:0 & ND & 1.441 & 2.860 & 2.747 & ND \\
\hline C14:0 & 1.595 & 0.633 & 1.275 & 1.256 & 1.820 \\
\hline C14:1 & 0.385 & ND & ND & 0.061 & 0.024 \\
\hline C15:0 & 0.131 & ND & ND & 0.115 & 0.033 \\
\hline C16:0 & 2.860 & 3.794 & 2.711 & 14.170 & 2.373 \\
\hline C16:1 & 0.271 & 1.317 & 0.020 & 0.423 & 0.372 \\
\hline C17:0 & 0.847 & ND & 3.233 & 1.220 & 1.851 \\
\hline $\mathrm{C} 17: 1$ & ND & ND & ND & ND & 0.148 \\
\hline C18:0 & 0.274 & 0.131 & 0.099 & 4.040 & 0.334 \\
\hline C18:1n-9 trans & ND & ND & ND & ND & 0.165 \\
\hline C18:1n-9 cis & 0.395 & 1.806 & 1.714 & 46.493 & 8.882 \\
\hline C18:1n-7 & 0.124 & 0.245 & 0.204 & 2.903 & 4.085 \\
\hline $\mathrm{C} 18: 2$ & ND & ND & ND & ND & 0.072 \\
\hline $\mathrm{C} 18: 2 \mathrm{n}-6 \mathrm{cis}$ & 1.831 & 10.979 & 8.044 & 24.130 & 7.229 \\
\hline C20:0 & ND & ND & ND & 0.257 & 0.096 \\
\hline C20:1 & 0.105 & ND & ND & ND & ND \\
\hline C18:3n-3 & 4.616 & 0.979 & 1.146 & 2.937 & 1.356 \\
\hline $\mathrm{C} 22: 0$ & 0.151 & ND & ND & 0.396 & ND \\
\hline C22:1 & ND & ND & ND & ND & 0.721 \\
\hline
\end{tabular}

${ }^{1} \mathrm{BBP}=$ bakery by-product.

${ }^{2} \mathrm{RSM}=$ rapeseed meal.

${ }^{3} \mathrm{ND}=$ not detectable.

bags were hand-washed with running cold water until the water was clear and kept at $-20^{\circ} \mathrm{C}$ for chemical composition analysis.

\section{Daily Measurements of Fermentation Characteristics}

The $\mathrm{pH}$ and redox potential of fermentor fluid samples were immediately determined using a $\mathrm{pH}$ meter (Seven Multi, Mettler-Toledo GmbH, Schwerzenbach, Switzerland) equipped with the respective electrodes (InLab Expert Pro-ISM for pH and Pt4805-DPA-SCS8/120 for redox, respectively; Mettler-Toledo $\mathrm{GmbH}$ ). The volume of effluent fluid was recorded to control the optimal buffer infusion. Daily gas volume was mea- sured by the water replacement method (Soliva and Hess, 2007) and gas composition was determined using an infrared detector (ATEX Biogas monitor Check BM 2000, Ansyco, Karlsruhe, Germany).

Concentration and composition of SCFA (acetate, propionate, n-butyrate, isobutyrate, n-valerate, isovalerate, and caproate) were analyzed by GC, as described previously (Qumar et al., 2016). Briefly, incubation fluid samples were thawed and then centrifuged at 20,000 $\times g$ for $25 \mathrm{~min}$ at $4^{\circ} \mathrm{C}$. The supernatant $(0.6 \mathrm{~mL})$ was transferred into a fresh tube and $0.2 \mathrm{~mL}$ of $\mathrm{HCl}(1.8 \mathrm{~mol} / \mathrm{L})$ was added, followed by $0.2 \mathrm{~mL}$ of the internal standard (4-methylvaleric acid, Sigma-Aldrich, St. Louis, MO). After centrifugation of the mixture at $20,000 \times \mathrm{g}$ for 25 
min at $4^{\circ} \mathrm{C}$, the clear supernatant was transferred into the GC vial. Analysis of SCFA concentrations was conducted via a GC apparatus (GC Model 8060 MS 172 DPFC, No. 950713, Fisons, Rodano, Italy), which was equipped with a flame-ionization detector and a $30 \mathrm{~m} \times$ $0.53 \mathrm{~mm}$ ID $\times 0.53 \mu \mathrm{m}$ film thickness capillary column (Trace TR Wax, Thermo Fisher Scientific, Waltham, MA). The injector and detector were at temperatures of 170 and $190^{\circ} \mathrm{C}$, respectively. Helium was used as carrier gas with a flow rate of $6 \mathrm{~mL} / \mathrm{min}$. Stratos Software (Stratos Version 4.5.0.0, Polymer Laboratories, Church Stretton, Shropshire, UK) was used for generation and evaluation of chromatograms.

The concentration of ammonia was determined using the indophenol reaction (Weatherburn, 1967). The fermentor fluid samples were thawed at room temperature and subsequently centrifuged at $15,115 \times g$ for 10 min. The clear supernatant was diluted with distilled water to obtain a concentration within the standard calibration curve. Ammonia and phenol were oxidized by sodium hydroxide in the presence of sodium nitroprusside and dichloroisocyanuric acid. The absorbance was measured at $655 \mathrm{~nm}$ using U3000 Spectrophotometer (INULA GmbH, Vienna, Austria) after $90 \mathrm{~min}$ of reaction.

\section{Chemical Composition Analysis}

Analyses of feed and feed residue samples were conducted in duplicate according to VDLUFA (2012). Prior to analyses, feed residue samples were pooled for each fermentor across the last $5 \mathrm{~d}$ of each experimental run and oven-dried at $65^{\circ} \mathrm{C}$ for $48 \mathrm{~h}$ and ground, passing through a 0.5-mm screen (Retsch, Haan, Germany). The DM of the feed and pre-dried residue samples was determined by oven drying at $100^{\circ} \mathrm{C}$ for $24 \mathrm{~h}$. Ash was analyzed by combustion of samples at a temperature of $580^{\circ} \mathrm{C}$ overnight. The $\mathrm{CP}$ content was determined using the Kjeldahl method. The content of NDF and ADF was analyzed separately with the Fiber Therm FT 12 (Gerhardt GmbH \& Co. KG, Königswinter, Germany) following Van Soest et al. (1991). Heat-stable $\alpha$-amylase and sodium sulfite were used in the NDF procedure and both fiber fractions were expressed exclusive residual ash. Ether extract (EE) was analyzed using a Soxhlet extractor (Extraction System B-811, Büchi, Flawil, Switzerland). Starch and the content of phytate-bound phosphorus were determined using commercially available kits (Megazyme, Wicklow, Ireland). Sugar was analyzed via the Luff-Schoorl method according to VDLUFA (2012). The P content was determined photometrically using the vanado-molybdate method, and $\mathrm{Ca}, \mathrm{Mg}, \mathrm{K}$, and $\mathrm{Na}$ were determined by flame atomic absorption spectrophotometry according to VDLUFA (2012). Apparent nutrient disappearance was calculated from the difference between the nutrient contents in the nylon bags before and after $48 \mathrm{~h}$ of incubation.

For the determination of the fatty acid profile, the 1-step methylation method by Sukhija and Palmquist (1988) was applied. Briefly, $0.5 \mathrm{~g}$ of feed samples was extracted and converted to methyl esters for $2 \mathrm{~h}$ at $70^{\circ} \mathrm{C}$ with toluene and $5 \%$ fresh methanolic $\mathrm{HCl}$ using nonadecanoic acid (C19:0, Sigma-Aldrich, Munich, Germany) as an internal standard. Subsequently, $5 \mathrm{~mL}$ of $6 \% \mathrm{~K}_{2} \mathrm{CO}_{3}$ was added followed by $2 \mathrm{~mL}$ of toluene. After centrifugation, $1 \mu \mathrm{L}$ of the organic layer (split 50:1) was analyzed on a GC (Agilent Technologies 7890A, Waldbronn, Germany) equipped with an Agilent HP-88 capillary column $(100 \mathrm{~m} \times 0.25 \mathrm{~mm}$ ID $\times 0.2 \mu \mathrm{m} \mathrm{d}_{\mathrm{f}}$ ), and flame-ionization detector. The flow rates of the carrier gases (hydrogen and synthetic air) were 35 and $350 \mathrm{~mL} \cdot \mathrm{min}^{-1}$, respectively. The injection port temperature and the detection temperature were $250^{\circ} \mathrm{C}$. Oven temperature was gradually increased to $170^{\circ} \mathrm{C}$ for $1 \mathrm{~min}$ followed by an increase to $200^{\circ} \mathrm{C}$ at $2^{\circ} \mathrm{C} \cdot \mathrm{min}^{-1}$. After $1 \mathrm{~min}$ at $200^{\circ} \mathrm{C}$, the temperature was increased by $8^{\circ} \mathrm{C} \cdot \mathrm{min}^{-1}$ to $230^{\circ} \mathrm{C}$, which was held for another 10 min. Commercial standard FAME mixtures (Supelco 37 Component FAME Mix, Supelco, Bellefonte, PA) were used.

\section{Genomic DNA Extraction}

All microbial analyses were conducted solely in the liquid phase. Prior to DNA extraction, frozen incubation fluid samples from the last 5 sampling days per fermentor and run, were thawed on ice, vortexed to mix the sample, pooled, and then a 1-mL subsample was taken for DNA isolation. The DNA was first enzymatically and mechanically lyzed using a bead beater (sterile ceramic beads, $1.4 \mathrm{~mm}$; FastPrep-24 5G, MP Biomedicals LLC, Santa Ana, CA) according to the previously published protocol (Kong et al., 2010) and then isolated using the QIAamp Fast DNA Stool Mini Kit (Qiagen, Hilden, Germany). Samples were mixed with the supplied buffer and then heated at $95^{\circ} \mathrm{C}$ for 5 min. Thereafter, PCR inhibitors were removed and purified DNA was eluted following the manufacturer's instructions. The isolated DNA concentration was determined by a Qubit 2.0 Fluorometer (Life Technologies, Carlsbad, CA) using the Qubit dsDNA HS Assay Kit (Life Technologies) and stored at $-20^{\circ} \mathrm{C}$ for further analysis.

Sequencing, Sequence Processing, and Analysis. One $20-\mu \mathrm{L}$ aliquot of each DNA sample was sent for amplicon sequencing using a MiSeq Illumina sequencing platform and paired-end technology (Microsynth AG, 
Balach, Switzerland). Sequencing targeted the V3-V5 hypervariable region of the $16 \mathrm{~S}$ rRNA gene using the primer set 357F (5'-CCTACGGGAGGCAGCAG-3') and 926R-HMP (5'-CCGTCAATTCMTTTRAGT-3') to produce an amplicon size of approximately $523 \mathrm{bp}$ (Peterson et al., 2009). Libraries were constructed by ligating sequencing adapters and indices onto purified PCR products using the Nextera XT Sample Preparation Kit (Illumina) according to the recommendations of the manufacturer. Equimolar amounts of each of the libraries were pooled and submitted for sequencing on an Illumina MiSeq Personal Sequencer using a 300-bp read length paired-end protocol. After sequencing, paired ends were stitched together by Microsynth, resulting in a total of 3.8 million unfiltered reads with an average of $503 \mathrm{nt}$ in length. Sequence quality control and analyses were performed using the QIIME pipeline (Caporaso et al., 2010). Sequences were first quality filtered following previously published recommendations (Bokulich et al., 2013) and then screened for chimeras using the gold.fa database and USEARCH algorithm, filtered, and then picked using UCLUST (Edgar, 2010). Finally, samples were aligned and clustered to define operational taxonomic units (OTU) using PyNAST (Caporaso et al., 2010) and the SILVA database (v128; accessed August 3, 2017; Quast et al., 2013; Yilmaz et al., 2014). The degree of similarity between sequences was defined as $97 \%$ to obtain OTU identity at the species level. Any OTU that clustered with less than 10 reads were manually removed. A total of 2,415,892 sequences clustered into 6,282 OTU for further analysis. All OTU with a relative abundance greater than $0.1 \%$ (191 OTU) were taken for statistical analysis. Secondary classification of the OTU was performed using the National Center for Biotechnology Information BLASTN 2.7.0+ (Zhang et al., 2000). For calculation of the nonparametric species, richness estimators Chao 1 and diversity indices Shannon and Simpson at QIIME analysis were used.

\section{Accession Numbers}

Sequencing data are available in the BioProject SRA database (https://www.ncbi.nlm.nih.gov/sra/) as PRJNA412439 under the accession numbers SAMN07714160 to SAMN07714198.

\section{Statistical Analyses}

Statistical analyses were performed by ANOVA using the MIXED procedure of SAS (version 9.2, SAS Institute Inc., Cary, NC). For each variable tested, the model included the fixed effects of dietary treatment, considering the variation between experimental runs as a random effect. For measurements taken daily, the sampling day was included as a fixed effect as well. To account for the covariation within experimental units, data obtained on the same fermentor at different times within one run were considered as repeated measurements with a first-order autoregressive variance-covariance matrix based on the lowest Akaike information criterion. Degrees of freedom were estimated with the method of Kenward-Roger. The pdiff option was used for each least squares means comparison. Furthermore, for assessing the overall effect of the BBP inclusion, an orthogonal contrast involving the average of the 3 $\mathrm{BBP}$ treatments versus CON was tested. Also, contrast analyses were performed to test linear effects of BBP inclusion level. Differences among LSM with $P \leq 0.05$ were considered as representing significant differences and differences among least squares means with $0.05<$ $P \leq 0.10$ were considered as representing a trend. Correlations between the microbial data and fermentation parameters were analyzed using Pearson correlation coefficient (PROC CORR of SAS).

\section{RESULTS}

\section{Chemical Composition of BBP}

Nutrient and fatty acid analyses of the feed ingredients used are summarized in Table 1. The BBP showed higher ash content $(3.1 \%)$ compared with wheat and rye $(1.7 \%)$. A closer look at macro minerals showed a higher content of $\mathrm{Na}$ in the by-product compared with the native cereals ( 6.5 vs. $0.14 \mathrm{~g} / \mathrm{kg}$ of DM). Analysis of the proportion of phytate-bound $\mathrm{P}$ in relation to total $\mathrm{P}$ revealed a decrease from about $56 \%$ in wheat and rye to $29 \%$ in the $\mathrm{BBP}$. Although the $\mathrm{CP}$ content was similar between wheat and $\mathrm{BBP}$, the NDF and $\mathrm{ADF}$ fractions decreased by half in the BBP. The content of EE was almost $12.2 \%$ in the BBP, and sugar amounted to $10.7 \%$. Besides an increase in the absolute amount of fatty acids in the BBP compared with the cereal grains, a shift in the profile also occurred. The ratio of UFA to SFA increased from 2.5 in wheat and 1.1 in rye, to 3.0 in the BBP, with oleic acid (C18:1n-9 cis) being the fatty acid with the highest concentration in the BBP ( $45 \%$ of the total amount of fatty acids compared with $8 \%$ in wheat and rye). Finally, a higher content of $\mathrm{NE}_{\mathrm{L}}$ was estimated for the BBP $(9.3 \mathrm{MJ} /$ $\mathrm{kg}$ of $\mathrm{DM})$ compared with wheat and rye $(8.5 \mathrm{MJ} / \mathrm{kg}$ of DM). The differences between cereals and the BBP are also reflected in the chemical composition of the different experimental diets (Table 2).

\section{Ruminal Fermentation}

Results of ruminal fermentation characteristics are shown in Table 3. An overall effect of BBP inclusion 
Table 2. Ingredients and chemical composition of diets either containing $45 \%$ grains (CON) or varying inclusion levels of bakery by-product (BBP)

\begin{tabular}{|c|c|c|c|c|}
\hline \multirow[b]{2}{*}{ Item } & \multicolumn{4}{|c|}{ Experimental diet ${ }^{1}$} \\
\hline & $\mathrm{CON}$ & $15 \% \mathrm{BBP}$ & $30 \% \mathrm{BBP}$ & $45 \% \mathrm{BBP}$ \\
\hline \multicolumn{5}{|l|}{$\overline{\text { Ingredient }(\% \text { of } \mathrm{DM})}$} \\
\hline Hay & 42 & 42 & 42 & 42 \\
\hline Wheat & 33.75 & 22.50 & 11.25 & - \\
\hline Rye & 11.25 & 7.5 & 3.75 & - \\
\hline $\mathrm{BBP}$ & - & 15 & 30 & 45 \\
\hline Rapeseed meal & 11 & 11 & 11 & 11 \\
\hline Vitamin-mineral premix ${ }^{2}$ & 1.7 & 1.7 & 1.7 & 1.7 \\
\hline Calcium carbonate & 0.3 & 0.3 & 0.3 & 0.3 \\
\hline \multicolumn{5}{|c|}{ Chemical composition (\% of DM unless stated) } \\
\hline $\mathrm{DM}$ (\% of fresh matter) & 89.2 & 90.1 & 91.0 & 91.2 \\
\hline Ash & 6.9 & 7.1 & 7.4 & 7.6 \\
\hline $\mathrm{CP}$ & 16.1 & 16.3 & 16.4 & 16.5 \\
\hline $\mathrm{NDF}$ & 34.3 & 33.4 & 32.4 & 31.5 \\
\hline $\mathrm{ADF}$ & 20.5 & 20.2 & 19.9 & 19.6 \\
\hline Ether extract & 2.5 & 4.0 & 5.5 & 7.1 \\
\hline Starch & 29.8 & 27.9 & 26.0 & 24.0 \\
\hline Sugars & 5.6 & 6.5 & 7.4 & 8.2 \\
\hline $\mathrm{NE}_{\mathrm{L}}(\mathrm{MJ} / \mathrm{kg}$ of $\mathrm{DM})$ & 6.81 & 6.93 & 7.05 & 7.16 \\
\hline Calcium & 0.65 & 0.66 & 0.67 & 0.67 \\
\hline Phosphorus & 0.49 & 0.47 & 0.46 & 0.44 \\
\hline Phytate-phosphorus & 0.15 & 0.13 & 0.12 & 0.10 \\
\hline Magnesium & 0.27 & 0.27 & 0.27 & 0.27 \\
\hline Potassium & 1.35 & 1.33 & 1.31 & 1.29 \\
\hline
\end{tabular}

${ }^{1}$ The diets included $45 \%$ cereal grains (CON), $15 \%$ BBP and $30 \%$ cereal grains (15\% BBP), $30 \%$ BBP and $15 \%$ cereal grains $(30 \% \mathrm{BBP})$, or $45 \% \mathrm{BBP}(45 \% \mathrm{BBP})$.

${ }^{2}$ Contained: $130 \mathrm{~g}$ of calcium, $45 \mathrm{~g}$ of phosphorus, $100 \mathrm{~g}$ of sodium, $30 \mathrm{~g}$ of magnesium, 1,000 $\mathrm{mg}$ of copper, $6,600 \mathrm{mg}$ of zinc, 4,500 $\mathrm{mg}$ of manganese, $40 \mathrm{mg}$ of selenium, $100 \mathrm{mg}$ of cobalt, $80 \mathrm{mg}$ of iodine, 700,000 IU of vitamin $\mathrm{A}, 100,000 \mathrm{IU}$ of vitamin $\mathrm{D}_{3}$, and $3,000 \mathrm{mg}$ of vitamin $\mathrm{E}$.

toward a decrease of the $\mathrm{pH}$ of incubation fluid was observed $(P=0.03)$. A more specific comparison revealed only minor differences between $\mathrm{CON}$ (6.63) and $45 \%$ BBP $(6.59, P=0.02)$. The redox potential and $\mathrm{CO}_{2}$ formation were not affected by dietary treatment. The methane formation was lowest with $45 \%$ BBP ( $P$ $=0.01$ ); however, no differences among groups were found when methane formation was related to degraded NDF $(P=0.47)$. The concentration of ammonia in the fermentor fluid was affected by the $\operatorname{diet}(P<0.01)$. Whereas the concentration was similar in $\mathrm{CON}$ and $15 \% \mathrm{BBP}$, a significant decrease was found in $30 \% \mathrm{BBP}$ $(-22.5 \%)$ and $45 \%$ BBP $(-33.0 \% ; P<0.01)$.

Dietary treatment did not alter total SCFA concentration $(P=0.92)$; however, differences in the SCFA profile were found among treatments (Table 3). Acetate proportion linearly decreased with increasing BBP inclusion levels $(P<0.01)$, with the maximum change in $45 \%$ BBP, showing an about $6.2 \%$ lower acetate proportion compared with $\mathrm{CON}(P<0.01)$. The propionate proportion was linearly increased from $18.6 \%$ in CON to $23.7 \%$ in $45 \%$ BBP $(P<0.01)$. These changes resulted in a strong decrease in the acetate-to-propionate ratio from 2.63 in $\mathrm{CON}$ to 1.94 in $45 \% \mathrm{BBP}(P<0.01)$. Whereas the butyrate proportion remained unaffected
$(P=0.35)$, isobutyrate linearly decreased with BBP level $(P<0.01)$, reaching a decrease of about $32 \%$ in $45 \%$ BBP compared with CON $(P<0.01)$. Enhancing the $\mathrm{BBP}$ inclusion level caused an increase in isovalerate $(P<0.01)$, whereas a linear decrease in caproate was found $(P<0.01)$.

\section{Nutrient Disappearance}

The disappearance of nutrients, especially starch $(P$ $=0.01$ ), was affected by dietary treatment (Table 3 ). The disappearance of DM was on average $3.1 \%$ lower in CON compared with the diets including BBP $(P<$ 0.01). A trend toward a linear effect of BBP inclusion level $(P=0.06)$ revealed higher ash disappearance in $45 \%$ BBP compared with $\mathrm{CON}(P=0.03)$ and $15 \%$ BBP $(P=0.06)$. The BBP in the diet decreased the disappearance of $\mathrm{CP}(P=0.01)$ by on average $3.1 \%$ compared with CON. The disappearance of starch in BBP diets was greater than in the $\mathrm{CON} \operatorname{diet}(P<$ 0.01 ), showing a strong linear increase from $84.4 \%$ $(\mathrm{CON})$ to almost $96.3 \%$ (45\% BBP). A linear effect of $\mathrm{BBP}$ on NDF disappearance was detected $(P<0.01)$, with $45 \%$ BBP decreasing this variable by $13.6 \%$ compared with CON $(P=0.01)$. However, no differences 
among the lower BBP inclusion levels and CON were observed $(P \geq 0.45)$. The disappearance of ADF was not affected by the dietary treatment $(P=0.64)$. The EE disappearance was increased by about $20 \%$ in the diets containing $\mathrm{BBP}(P<0.01)$.

\section{Ruminal Microbiota}

Diversity indices and evenness estimators of the rumen community measured in the liquid phase are summarized in Table 4. Numbers of OTU as well as the species richness based on Chao I did not differ between diets. Species diversity based on the Simpson and Shannon indices was lower in $45 \% \mathrm{BBP}$ compared with CON $(P=0.04)$.

In total, 19 phyla were identified, with Bacteroidetes and Firmicutes being the most abundant with total relative abundances of 54.9 and $37.3 \%$, respectively (Table 5). No overall effect of the BBP inclusion was found on the phylum level.
According to the OTU assignment, a total of $34.71 \%$ of the OTU could be assigned to 83 genera, 15 of them being affected by the inclusion of BBP (Figure 1). Data on the genera that were not affected by the BBP are summarized in Supplemental Table S1 (https://doi.org/ 10.3168/jds.2017-14051). The most abundant genus, Prevotella (24.95\% total relative abundance), tended to be increased by the BBP inclusion $(P=0.10)$. Furthermore, orthogonal contrast analysis revealed an increase of Roseburia, Megasphaera, p-75a-5, and Acidaminococcus $(P \leq 0.05)$, as well as a trend toward an increase of $P S B-M-3$, Atopobium, and Syntrophomonas $(P \leq 0.09)$. In contrast, the genera Butyrivibrio, Anaerostipes, Shuttleworthia, and Azospirillium were decreased when $\mathrm{BBP}$ was used as a substitute for grains $(P \leq 0.09)$. A linear effect for Mogibacterium $(P=0.02)$ revealed an increase with BBP level. Oppositely, the genus Agrobacterium was linearly decreased with the BBP level $(P=0.02)$.

Figure 2 provides a list of the OTU that were affected by the BBP inclusion, within the first most

Table 3. Fermentation characteristics and nutrient degradability as affected by the inclusion level of bakery by-product (BBP)

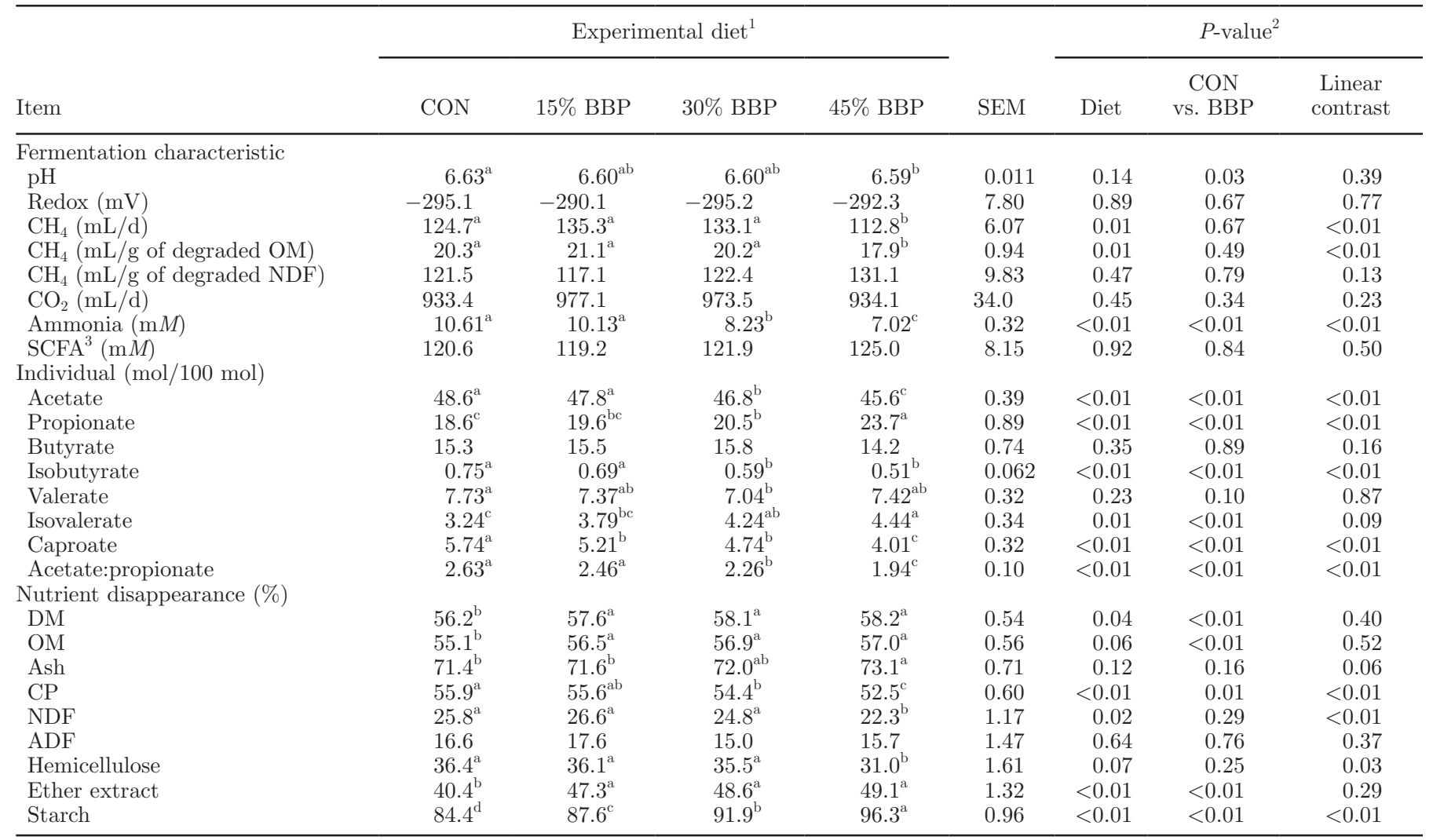

\footnotetext{
${ }^{\mathrm{a}-\mathrm{d}}$ Different superscripts indicate differences among LSM in the same row at $P \leq 0.05$.

${ }^{1}$ The diets included $45 \%$ cereal grains $(\mathrm{CON}), 15 \% \mathrm{BBP}$ and $30 \%$ cereal grains $(15 \% \mathrm{BBP}), 30 \% \mathrm{BBP}$ and $15 \%$ cereal grains $(30 \% \mathrm{BBP})$, or $45 \%$ BBP (45\% BBP).

${ }^{2}$ Effect of experimental diet (Diet), overall effect of BBP inclusion (CON vs. BBP), and linear effect of BBP inclusion level (linear contrast). ${ }^{3} \mathrm{SCFA}=$ short-chain fatty acids.
} 
Table 4. Diversity indices and evenness estimators of the rumen community measured in the liquid phase as affected by the inclusion level of bakery by-product (BBP)

\begin{tabular}{|c|c|c|c|c|c|c|c|c|}
\hline \multirow[b]{2}{*}{ Diversity } & \multicolumn{4}{|c|}{ Experimental $\operatorname{diet}^{1}$} & \multirow[b]{2}{*}{ SEM } & \multicolumn{3}{|c|}{$P$-value ${ }^{2}$} \\
\hline & $\mathrm{CON}$ & $15 \% \mathrm{BBP}$ & $30 \% \mathrm{BBP}$ & $45 \% \mathrm{BBP}$ & & Diet & $\begin{array}{c}\text { CON vs. } \\
\text { BBP }\end{array}$ & $\begin{array}{l}\text { Linear } \\
\text { contrast }\end{array}$ \\
\hline Chao I & $4,417.42$ & $4,075.27$ & $4,370.64$ & $4,083.80$ & 238 & 0.54 & 0.34 & 0.98 \\
\hline Shannon & $9.26^{\mathrm{a}}$ & $8.92^{\mathrm{ab}}$ & $9.10^{\mathrm{ab}}$ & $8.69^{\mathrm{b}}$ & 0.291 & 0.20 & 0.11 & 0.41 \\
\hline Simpson & $0.9942^{\mathrm{a}}$ & $0.9920^{\mathrm{ab}}$ & $0.9928^{\mathrm{ab}}$ & $0.9898^{\mathrm{b}}$ & 0.002 & 0.19 & 0.11 & 0.29 \\
\hline Observed OTU ${ }^{3}$ & 3,412 & 3,069 & 3,242 & 2,976 & 190 & 0.39 & 0.16 & 0.73 \\
\hline
\end{tabular}

$\overline{\mathrm{a}, \mathrm{b}}$ Different superscripts indicate differences among LSM in the same row at $P \leq 0.05$.

${ }^{1}$ The diets included $45 \%$ cereal grains (CON), $15 \%$ BBP and $30 \%$ cereal grains (15\% BBP), $30 \%$ BBP and $15 \%$ cereal grains $(30 \% \mathrm{BBP})$, or $45 \% \mathrm{BBP}(45 \% \mathrm{BBP})$.

${ }^{2}$ Effect of experimental diet (Diet), overall effect of BBP inclusion (CON vs. BBP), and linear effect of BBP inclusion level (linear contrast).

${ }^{3} \mathrm{OTU}=$ operational taxonomic unit.

abundant 191 OTU, representing those with a total relative abundance of $\geq 0.10 \%$. Overall, 22 OTU were affected by the inclusion of the BBP. Similar to the genera data, the most abundant OTU, OTU_1 (Prevotella ruminicola), was increased when BBP was included in the diets $(P=0.05)$, whereby the increase was especially pronounced in $30 \% \mathrm{BBP}(+27 \%, P=0.06)$ and $45 \%$ BBP $(+32 \% P=0.03)$. Similarly, Roseburia faecis (OTU_20) was increased by on average 67\% ( $P$ $=0.02$ in the diets containing BBP, again with only $30 \% \mathrm{BBP}$ and $45 \% \mathrm{BBP}$ differing significantly from CON $(P=0.03)$. Also, Megasphaera (OTU_63) was enhanced by on average $69 \%$ in the BBP diets $(P=$ 0.05). A significant effect of BBP toward an increase was also noticed for OTU_36 (Clostridiales), OTU_69 (Christensenellaceae), OTU_112 (Coprococcus), and OTU_113 (Acidaminococcus fermentans), whereas the orthogonal contrast analysis revealed a decrease of OTU_67 (Bacteroidales), OTU_96 (Clostridiales), and OTU_125 and OTU_172 (Ruminococcaceae). A linear effect for OTU_4 (Clostridiales) found an increase with BBP level. Also for OTU_37, OTU_82, and OTU_120 (Bacteroidales), as well as for the OTU_115 (Prevotella) and OTU_157 (CF231), a linear increase with the

Table 5. Phyla measured in the liquid phase as affected by the inclusion level of bakery by-product (BBP)

\begin{tabular}{|c|c|c|c|c|c|c|c|c|c|}
\hline \multirow[b]{2}{*}{ Phylum } & \multirow[b]{2}{*}{$\begin{array}{l}\text { Total relative } \\
\text { abundance }(\%)\end{array}$} & \multicolumn{4}{|c|}{ Experimental diet ${ }^{1}$} & \multirow[b]{2}{*}{ SEM } & \multicolumn{3}{|c|}{$P$-value ${ }^{2}$} \\
\hline & & $\mathrm{CON}$ & $15 \% \mathrm{BBP}$ & $30 \% \mathrm{BBP}$ & $45 \% \mathrm{BBP}$ & & Diet & $\begin{array}{l}\text { CON vs. } \\
\text { BBP }\end{array}$ & $\begin{array}{c}\text { Linear } \\
\text { contrast }\end{array}$ \\
\hline Bacteroidetes & 54.877 & 54.20 & 54.97 & 54.73 & 55.61 & 1.347 & 0.79 & 0.44 & 0.65 \\
\hline Firmicutes & 37.258 & 37.40 & 36.57 & 37.67 & 37.40 & 0.9897 & 0.81 & 0.85 & 0.49 \\
\hline Spirochaetes & 1.909 & $1.950^{\mathrm{yz}}$ & $1.729^{\mathrm{z}}$ & $2.140^{\mathrm{y}}$ & $1.816^{\mathrm{yz}}$ & 0.4444 & 0.22 & 0.73 & 0.67 \\
\hline Proteobacteria & 0.762 & 0.865 & 0.953 & 0.573 & 0.658 & 0.1919 & 0.35 & 0.48 & 0.22 \\
\hline Cyanobacteria & 0.757 & 1.207 & 0.883 & 0.410 & 0.529 & 0.0059 & 0.53 & 0.22 & 0.55 \\
\hline Lentisphaerae & 0.716 & 0.642 & 0.702 & 0.800 & 0.721 & 0.1995 & 0.66 & 0.34 & 0.88 \\
\hline Synergistetes & 0.614 & 0.441 & 0.899 & 0.499 & 0.616 & 0.2458 & 0.38 & 0.32 & 0.32 \\
\hline Verrucomicrobia & 0.465 & 0.461 & 0.437 & 0.509 & 0.455 & 0.1035 & 0.80 & 0.92 & 0.81 \\
\hline Tenericutes & 0.463 & 0.687 & 0.491 & 0.401 & 0.271 & 0.2261 & 0.57 & 0.23 & 0.47 \\
\hline Elusimicrobia & 0.350 & $0.379^{\mathrm{ab}}$ & $0.276^{\mathrm{b}}$ & $0.460^{\mathrm{a}}$ & $0.283^{\mathrm{b}}$ & 0.0011 & 0.03 & 0.47 & 0.91 \\
\hline TMY & 0.273 & $0.315^{\mathrm{a}}$ & $0.198^{\mathrm{b}}$ & $0.326^{\mathrm{a}}$ & $0.254^{\mathrm{ab}}$ & 0.0896 & 0.12 & 0.25 & 0.34 \\
\hline Actinobacteria & 0.226 & 0.221 & 0.225 & 0.213 & 0.244 & 0.0295 & 0.64 & 0.74 & 0.44 \\
\hline Fibrobacteres & 0.205 & 0.217 & 0.336 & 0.156 & 0.110 & 0.0013 & 0.63 & 0.91 & 0.22 \\
\hline$W P S-2$ & 0.032 & 0.036 & 0.038 & 0.021 & 0.035 & 0.0172 & 0.28 & 0.56 & 0.73 \\
\hline Fusobacteria & 0.030 & $0.024^{\mathrm{z}}$ & $0.049^{\mathrm{y}}$ & $0.023^{\mathrm{Z}}$ & $0.025^{\mathrm{z}}$ & 0.0098 & 0.16 & 0.41 & 0.07 \\
\hline Chloroflexi & 0.017 & $0.017^{\mathrm{yz}}$ & $0.015^{\mathrm{z}}$ & $0.023^{\mathrm{y}}$ & $0.014^{\mathrm{z}}$ & 0.0049 & 0.16 & 0.81 & 0.84 \\
\hline$S R 1$ & 0.016 & 0.027 & 0.025 & 0.005 & 0.005 & 0.0155 & 0.50 & 0.34 & 0.30 \\
\hline Planctomycetes & 0.008 & 0.006 & 0.006 & 0.01 & 0.009 & 0.0021 & 0.46 & 0.50 & 0.30 \\
\hline Armatimonadetes & 0.003 & 0.002 & 0.003 & 0.005 & 0.003 & 0.0012 & 0.13 & 0.27 & 0.77 \\
\hline
\end{tabular}

$\overline{a, b}$ Different superscripts indicate differences among LSM in the same row at $P \leq 0.05$.

${ }^{y, z}$ Different superscripts indicate differences among LSM in the same row at $P \leq 0.10$.

${ }^{1}$ The diets included $45 \%$ cereal grains (CON), $15 \%$ BBP and $30 \%$ cereal grains (15\% BBP), $30 \%$ BBP and $15 \%$ cereal grains (30\% BBP), or $45 \%$ BBP $(45 \%$ BBP).

${ }^{2}$ Effect of experimental diet (Diet), overall effect of BBP inclusion (CON vs. BBP), and linear effect of BBP inclusion level (linear contrast). 


\begin{tabular}{|c|c|c|c|c|c|c|c|c|c|}
\hline \multirow[b]{2}{*}{ Genus } & \multirow[b]{2}{*}{$\begin{array}{c}\text { total relative } \\
\text { abundance }(\%)\end{array}$} & \multicolumn{4}{|c|}{ Experimental diets ${ }^{1}$} & \multirow[b]{2}{*}{ SEM } & \multicolumn{3}{|c|}{$P$-value ${ }^{2}$} \\
\hline & & $\mathrm{CON}$ & $\begin{array}{l}15 \% \\
\text { BBP }\end{array}$ & $\begin{array}{l}30 \% \\
\mathrm{BBP}\end{array}$ & $\begin{array}{l}45 \% \\
\text { BBP }\end{array}$ & & Diet & $\begin{array}{c}\text { CON vs. } \\
\text { BBP }\end{array}$ & $\begin{array}{c}\text { Linear } \\
\text { Contrast }\end{array}$ \\
\hline Prevotella & 24.95 & & $\dot{\dagger}$ & & $\dot{\dagger}$ & 1.3010 & 0.15 & 0.10 & 0.97 \\
\hline Roseburia & 0.681 & & & * & * & 0.1499 & 0.10 & 0.02 & 0.36 \\
\hline Butyrivibrio & 0.560 & & & & & 0.1250 & 0.40 & 0.09 & 0.80 \\
\hline Megasphaera & 0.252 & & $\dagger$ & & $\dagger$ & 0.0493 & 0.19 & 0.05 & 0.98 \\
\hline$p-75 a-5$ & 0.212 & & * & & $*$ & 0.0329 & 0.02 & 0.03 & 0.50 \\
\hline Acidaminococcus & 0.172 & & & $\dagger$ & $*$ & 0.0389 & 0.05 & 0.02 & 0.14 \\
\hline Paludibacter & 0.109 & & $*$ & $\dagger$ & $*$ & 0.0226 & 0.06 & 0.67 & 0.49 \\
\hline Anaerostipes & 0.0573 & & $\dagger$ & & $*$ & 0.0207 & 0.09 & 0.08 & 0.65 \\
\hline$P S B-M-3$ & 0.0282 & & & $\dagger$ & & 0.0039 & 0.34 & 0.07 & 0.96 \\
\hline Mogibacterium & 0.0276 & & & & * & 0.0037 & 0.06 & 0.48 & 0.02 \\
\hline Shuttleworthia & 0.0229 & & & & $\dagger$ & 0.0090 & 0.35 & 0.09 & 0.62 \\
\hline Atopobium & 0.0115 & & * & & & 0.0018 & 0.20 & 0.09 & 0.41 \\
\hline Agrobacterium & 0.0031 & & $*$ & & & 0.00001 & $<0.01$ & 0.12 & 0.04 \\
\hline Syntrophomonas & 0.0026 & & & $\dagger$ & & 0.00001 & 0.36 & 0.09 & 0.81 \\
\hline Azospirillum & 0.0025 & & $*$ & & $\dagger$ & 0.00001 & 0.19 & 0.04 & 0.70 \\
\hline
\end{tabular}

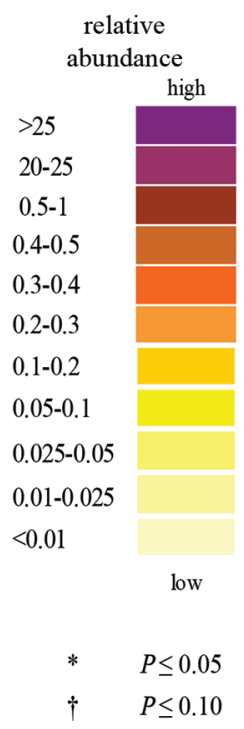

Figure 1. Genera measured in the liquid phase as affected by the inclusion level of bakery by-product (BBP). *Differences of the BBP diets compared with CON at $P \leq 0.05$. $\dagger$ Differences at $P \leq 0.10 .{ }^{1}$ The diets included $45 \%$ cereal grains (CON), $15 \%$ BBP and $30 \%$ cereal grains $(15 \%$ $\mathrm{BBP}$ ), 30\% BBP and 15\% cereal grains (30\% BBP), or $45 \%$ BBP (45\% BBP). ${ }^{2}$ Effect of experimental diet (Diet), overall effect of BBP inclusion (CON vs. BBP), and linear effect of BBP inclusion level (linear contrast). Color version available online.

BBP inclusion was found $(P \leq 0.04)$. On the contrary, OTU_185 (Bacteroidales) was linearly decreased, with the $45 \%$ BBP tending to differ from CON $(P=0.06)$.

\section{Correlation Analysis}

Figure 3a shows significant correlations among OTU and the disappearance of starch $(P \leq 0.05)$. The highest positive associations were found for $A$. fermentans (OTU_113), Prevotella sp.-associated OTU (OTU_1, OTU_115, OTU_78, OTU_191, and OTU_182), and Roseburia faecis (OTU_20). Among the OTU being negatively associated with the $\mathrm{pH}$ (Figure 3b), mainly $P$. ruminicola (OTU_1, OTU_182, and OTU_162) showed significant correlations $(P \leq 0.05)$. Also, Christenenellaceae (OTU_69), Clostridiales (OTU_36), Coprococcus (OTU_112), and Roseburia faecis (OTU_20) were negatively correlated with the ruminal $\mathrm{pH}(P \leq$ 0.07). In contrast, mainly OTU belonging to Bacteroidales (OTU_139, OTU_67, OTU_151, OTU_158 and OTU_133) and Ruminococcaceae (OTU_125 and OTU_181) showed a positive association with $\mathrm{pH}(P$ $\leq 0.07)$.

\section{DISCUSSION}

The present study was performed to evaluate the effect of the gradual replacement of cereal grains by BBP on ruminal fermentation characteristics, nutrient degradation, and microbial community composition in vitro.
One main finding of the study was that substitution of common cereals such as wheat and rye up to two-thirds did not impair ruminal $\mathrm{pH}$, nutrient degradation, or microbial diversity. Indeed, whereas fiber degradation remained unchanged up to an inclusion rate of $30 \%$ $\mathrm{BBP}$ in the diet, DM and starch degradation linearly increased.

Although total SCFA concentration was not affected, decreased acetate, isobutyrate, valerate, and caproate, and increased propionate and isovalerate levels clearly showed that inclusion of BBP modulated microbial metabolic activity when compared with the control treatment. However, one has to consider that the SCFA analysis gives no information regarding the production of SCFA except concentration. Thus, it is possible that the higher provision of rapidly degradable carbohydrates in the diets containing BBP might have enhanced the total production of SCFA, as supported by the overall reducing effect on ruminal $\mathrm{pH}$. Moreover, it is also possible that the time of sampling $(23 \mathrm{~h}$ after incubation) might be a reason for the insignificant differences among groups. Thus, a more frequent sampling, especially in the early hours after the incubation of fresh feed, should be considered in further in vivo studies.

The replacement of cereal grains by BBP increased the proportion of easily degradable NFC, most importantly starch, in the diets. Moreover, higher levels of sugars were present in the BBP compared with the native grains. Therefore, the decrease in the ratio of 
acetate to propionate reflects these changes in the nutrient composition as well as in the enhanced degradation of starch.

Our study revealed a decreased methane formation when cereal grains were fully replaced by the BBP. This is likely due to the enhanced fat content or the reduced content of degradable NDF of the diet (or both), as both diet components have been reported to have a profound effect on methane emission in cattle. Although $\mathrm{NDF}$ is generally known to promote the formation of methane (Jayanegara et al., 2010), fat has an opposite effect (Hünerberg et al., 2013). Thus, when taking the reduced NDF degradability of the $45 \%$ BBP diet into account, the reducing effect on methane diminished. Therefore, the methane-mitigating effect of the $45 \%$ $\mathrm{BBP}$ diet seems to be of limited benefit, as it happened at the expense of fiber degradability.

So far only one study has investigated the effect of the substitution of cereals with BBP on ruminal fermentation parameters (Franca et al., 2012). In line with

\begin{tabular}{|c|c|c|c|c|c|c|c|c|c|c|c|c|}
\hline \multirow[b]{2}{*}{$\begin{array}{l}\text { OTU } \\
\text { Number }\end{array}$} & \multirow[b]{2}{*}{ Classification } & \multirow[b]{2}{*}{$\begin{array}{c}\text { total relative } \\
\text { abundance }(\%)\end{array}$} & \multicolumn{4}{|c|}{ Experimental diets $^{1}$} & \multirow[b]{2}{*}{ SEM } & \multicolumn{3}{|c|}{$P$-value ${ }^{2}$} & & \\
\hline & & & $\mathrm{CON}$ & $15 \% \mathrm{BBP}$ & $30 \% \mathrm{BBP}$ & $45 \% \mathrm{BBP}$ & & Diet & $\begin{array}{c}\text { CON vs } \\
\text { BBP }\end{array}$ & $\begin{array}{c}\text { Linear } \\
\text { Contrast }\end{array}$ & & \\
\hline$\overline{\text { OTU_1 }}$ & Prevotella ruminicola (s) & 3.381 & & & + & * & $\overline{0.693}$ & 30.10 & 0.05 & 0.14 & & \\
\hline OTU_4 & Clostridiales (o) & 1.638 & & & & * & 0.457 & 70.10 & 0.37 & 0.03 & & \\
\hline OTU_5 & Lactobacillus mucosae (s) & 1.636 & & & $*$ & . & 0.414 & 40.06 & 0.39 & 0.61 & & \\
\hline OTU_20 & Roseburia faecis (s) & 0.600 & & & $*$ & $*$ & 0.134 & 40.09 & 0.02 & 0.36 & & \\
\hline OTU_25 & Lactobacillus ultunensis (s) & 0.581 & & & + & + & 0.132 & 0.29 & 0.06 & 0.69 & & \\
\hline OTU_36 & Clostridiales (o) & 0.376 & & * & * & * & 0.143 & 30.02 & $<0.01$ & 0.74 & & \\
\hline OTU_37 & Bacteroidales (o) & 0.342 & & * & & 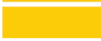 & 0.110 & 0.01 & 0.88 & 0.01 & & \\
\hline OTU_45 & Ruminococcaceae $(f)$ & 0.295 & & * & & * & 0.047 & 0.07 & 0.08 & 0.91 & & \\
\hline OTU_51 & Clostridiales (o) & 0.252 & & & & $\dagger$ & 0.105 & 0.17 & 0.39 & 0.07 & & \\
\hline OTU_63 & Megasphaera (g) & 0.252 & & + & & $t$ & 0.049 & 0.19 & 0.05 & 0.98 & relative & bundance \\
\hline OTU_67 & Bacteroidales (o) & 0.241 & & * & & * & 0.056 & 60.07 & 0.03 & 0.66 & & high \\
\hline OTU_68 & Prevotella (g) & 0.245 & & * & & & 0.082 & 20.15 & 0.07 & 0.46 & $3-5$ & \\
\hline OTU_69 & Christensenellaceae (f) & 0.253 & & & & * & 0.051 & 0.02 & 0.03 & 0.08 & $2.5-3$ & \\
\hline OTU_76 & CF231 (g) & 0.229 & & & + & 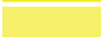 & 0.046 & 60.11 & 0.20 & 0.08 & $1.5-2.5$ & \\
\hline OTU_82 & Bacteroidales (o) & 0.209 & & * & & . & 0.052 & 20.01 & 0.86 & 0.03 & $1-1.5$ & \\
\hline OTU 86 & Ruminococcaceae $(f)$ & 0.210 & & & $\dagger$ & $\dagger$ & 0.127 & 70.19 & 0.10 & 0.22 & $0.5-1$ & \\
\hline OTU 91 & $B S 11(f)$ & 0.165 & & & & $*$ & 0.095 & 0.21 & 0.07 & 0.39 & $0.4-0.5$ & \\
\hline OTU 95 & Butyrivibrio hungatei (s) & 0.180 & & + & & 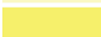 & 0.037 & 70.20 & 0.21 & 0.08 & $0.3-0.4$ & \\
\hline OTU_96 & Clostridiales (o) & 0.186 & & * & & * & 0.099 & 0.04 & 0.01 & 0.52 & $0.2-0.3$ & \\
\hline OTU_103 & Bacteroidales (o) & 0.132 & & & & + & 0.157 & 70.15 & 0.42 & 0.06 & $0.1-0.2$ & \\
\hline OTU_107 & Endomicrobia (c) & 0.183 & & & * & & 0.080 & 0.01 & 0.65 & 0.70 & $<0.1$ & \\
\hline OTU_109 & Bacteroidales (o) & 0.166 & & + & & $*$ & 0.034 & 40.05 & 0.19 & 0.83 & & low \\
\hline OTU_112 & Coprococcus (g) & 0.171 & & + & $\dagger$ & + & 0.104 & 40.20 & 0.04 & 0.79 & & \\
\hline OTU_113 & Acidaminococcus fermentans (s) & 0.151 & & & $*$ & $*$ & 0.053 & 30.00 & 0.01 & 0.01 & $*$ & $P \leq 0.05$ \\
\hline OTU_115 & Prevotella (g) & 0.155 & & & & + & 0.027 & 70.17 & 0.45 & 0.04 & $\dagger$ & $P \leq 0.10$ \\
\hline OTU_117 & Prevotella (g) & 0.156 & & & + & & 0.053 & 0.07 & 0.59 & 0.11 & & \\
\hline OTU_120 & Bacteroidales (o) & 0.152 & & & & * & 0.048 & 80.02 & 0.42 & $<0.01$ & & \\
\hline OTU_121 & Ruminococcaceae (f) & 0.156 & & $*$ & & * & 0.028 & 0.02 & 0.06 & 0.71 & & \\
\hline OTU_125 & Ruminococcaceae (f) & 0.131 & & * & & * & 0.072 & 20.05 & 0.03 & 0.98 & & \\
\hline OTU_128 & $B S 11(g)$ & 0.151 & & & * & & 0.075 & 0.03 & 0.06 & 0.49 & & \\
\hline OTU_132 & Ruminococcaceae (f) & 0.136 & & $\dagger$ & & & 0.043 & 30.09 & 0.35 & 0.47 & & \\
\hline OTU_133 & Bacteroidales (o) & 0.131 & & & & $\dagger$ & 0.036 & 60.22 & 0.10 & 0.72 & & \\
\hline OTU_147 & Roseburia intestinalis (s) & 0.131 & & & $\dagger$ & & 0.032 & 20.33 & 0.08 & 0.97 & & \\
\hline OTU_155 & $p-75-a 5(g)$ & 0.121 & & & & $*$ & 0.018 & 0.03 & 0.12 & 0.31 & & \\
\hline OTU_156 & $R 4-45 B(f)$ & 0.134 & & & * & & 0.051 & 0.08 & 0.13 & 0.50 & & \\
\hline OTU_157 & $C F 231(\mathrm{~g})$ & 0.130 & & + & & & 0.042 & 0.12 & 0.70 & 0.04 & & \\
\hline OTU_164 & Coprococcus (g) & 0.139 & & + & & * & 0.050 & 0.04 & 0.07 & 0.48 & & \\
\hline OTU_172 & Ruminococcaceae (f) & 0.111 & & * & & * & 0.021 & 0.01 & 0.02 & 0.83 & & \\
\hline OTU_175 & Paraprevotellaceae (f) & 0.109 & & * & & & 0.024 & 40.04 & 0.14 & 0.07 & & \\
\hline OTU_185 & Bacteroidales (o) & 0.083 & & & & $\dagger$ & 0.037 & 0.11 & 0.17 & 0.05 & & \\
\hline OTU_186 & Ruminococcaceae (f) & 0.097 & & * & & & 0.022 & 20.04 & 0.09 & 0.32 & & \\
\hline
\end{tabular}

Figure 2. Operational taxonomic units (OTU) measured in the liquid phase as affected by the inclusion level of bakery by-product (BBP). ${ }^{*}$ Differences of the BBP diets compared with $\mathrm{CON}$ at $P \leq 0.05$. $\dagger$ Differences at $P \leq 0.10 .{ }^{1}$ The diets included $45 \%$ cereal grains $(\mathrm{CON}), 15 \%$ $\mathrm{BBP}$ and $30 \%$ cereal grains (15\% BBP), 30\% BBP and $15 \%$ cereal grains $(30 \% \mathrm{BBP})$, or $45 \% \mathrm{BBP}(45 \% \mathrm{BBP}) .{ }^{2} \mathrm{Effect}$ of experimental diet (Diet), overall effect of BBP inclusion (CON vs. BBP), and linear effect of BBP inclusion level (linear contrast). Color version available online. 


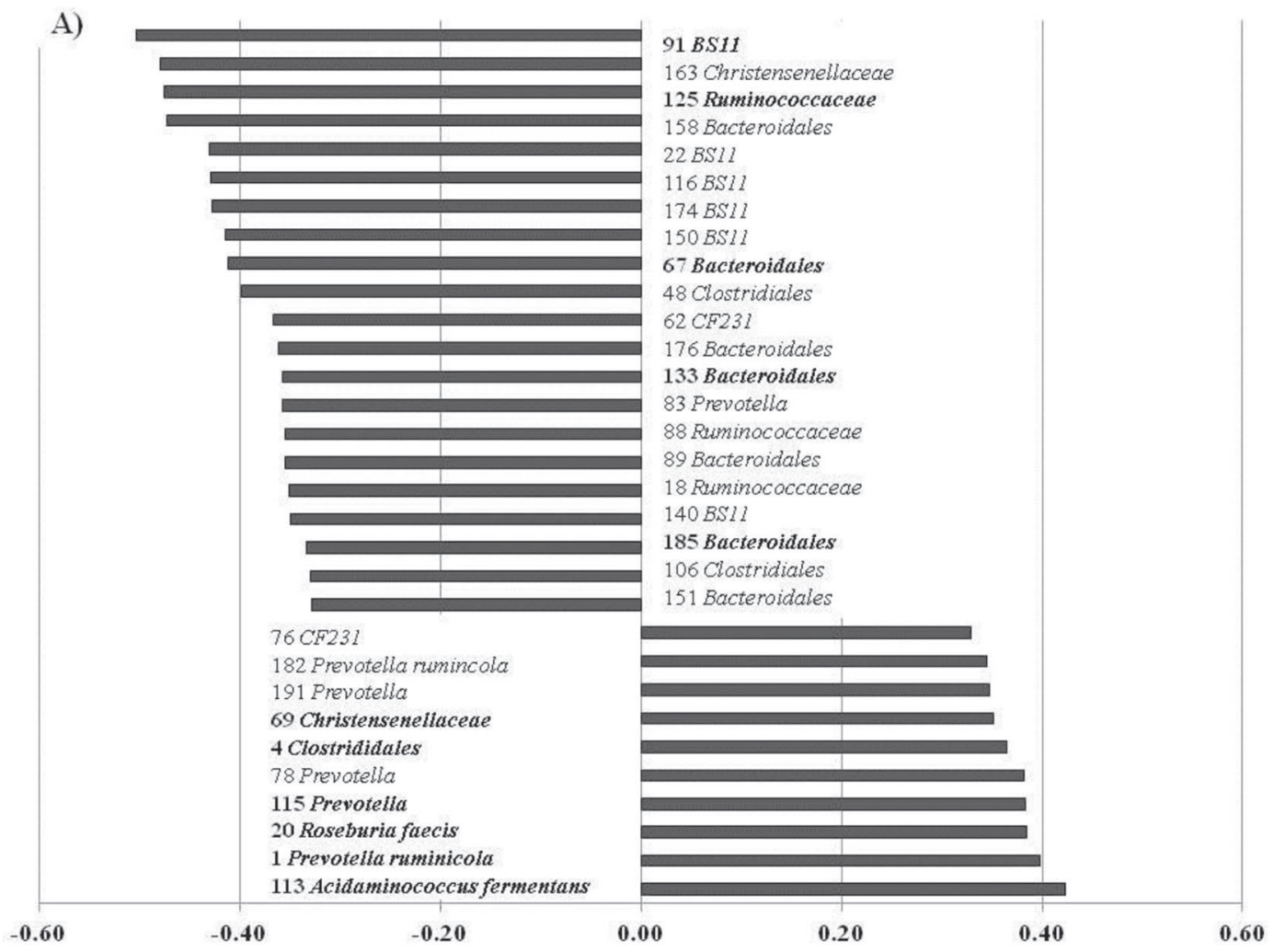

B)

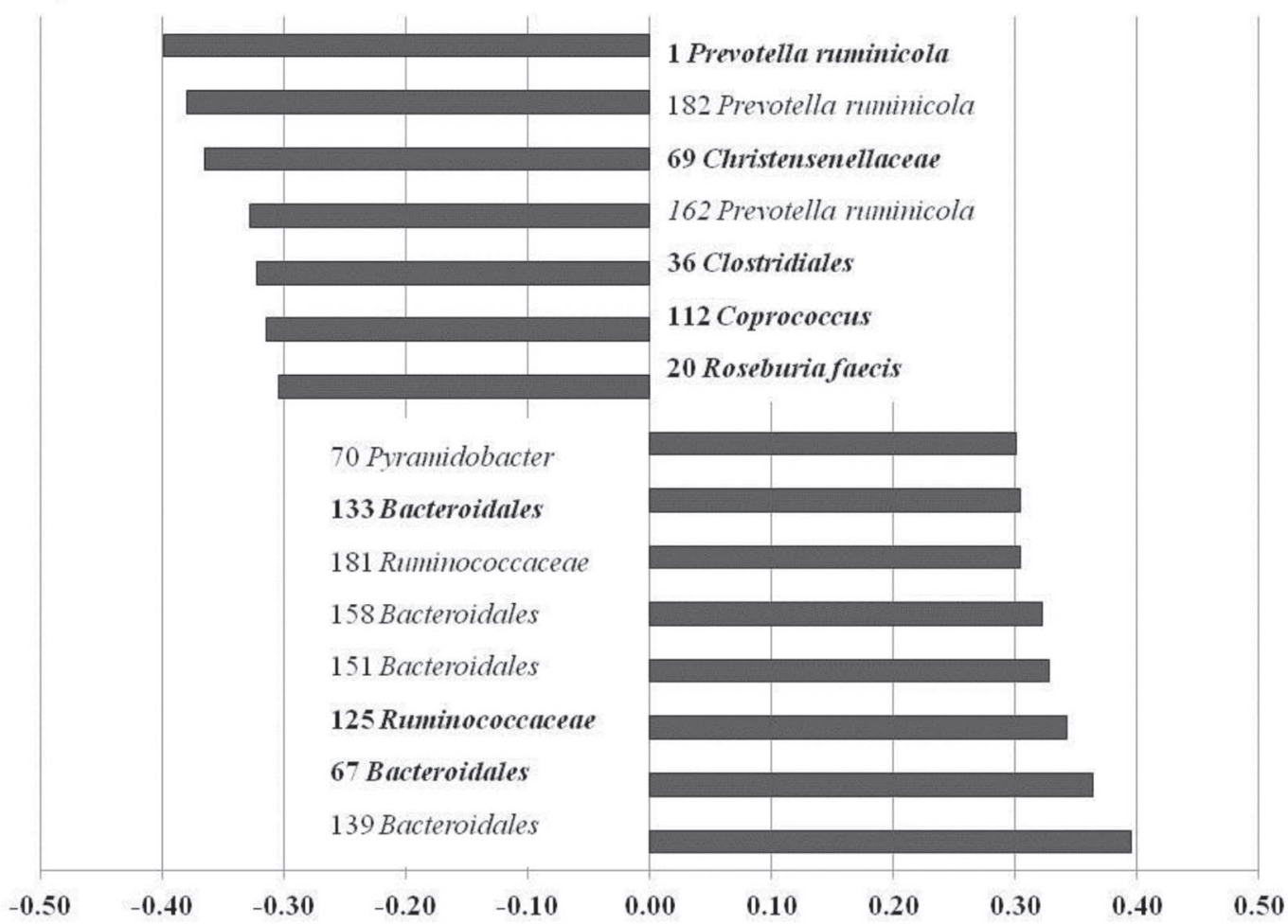

Figure 3. Bar graphs showing the operational taxonomic units (OTU) measured in the liquid phase correlating with the starch disappearance (A) and the $\mathrm{pH}(\mathrm{B})$. The OTU affected by the inclusion of the bakery by-product are shown in bold. The $\mathrm{x}$-axis indicates Pearson correlation coefficients. 
our results, an inclusion level of BBP up to $30 \%$ did not affect ruminal $\mathrm{pH}$ and concentration of SCFA, whereas a decreased ammonia level was observed. Thus, it is likely that besides a decrease in protein degradability, the increased energy availability (mainly due to the higher content of readily degradable carbohydrates in the BBP diets) for microbial protein synthesis caused the linear decrease in ruminal ammonia concentration. In accordance, the proportion of isobutyrate, the end product of ruminal deamination of dietary AA (Wallace, 1994), decreased. However, a linear increase in the molar proportion of isovalerate with increasing BBP level was noticed. A possible reason might be that this branched-chain fatty acid is linked to varying bacterial crossfeeding and changes in the microbial community. More specifically, recent studies suggest that the common rumen fibrolytic bacteria require branched-chain SCFA for the synthesis of branched-chain lipids (Suen et al., 2011a,b). Therefore, the higher abundance of fiber-fermenting bacteria (i.e., the genus Butyrivibrio and several OTU belonging to Ruminococcaceae in the CON group) might have caused an enhanced utilization of isovalerate.

Enhanced DM degradation is in line with a previous in situ degradation study conducted in fistulated sheep fed increasing BBP levels as a substitute for barley (Afzalzadeh et al., 2007). To the authors' knowledge, no further studies regarding the ruminal disappearance of diets including BBP are available. However, based on measurements on the total-tract level, contradictory effects of the inclusion of BBP on the digestibility have been reported, showing either no effect of the substitution of BBP for cereal grains (Franca et al., 2012; Obeidat et al., 2012) or a decrease in the digestibility of CP (Haddad and Ereifej, 2004).

One of the main aims of this study was to determine the effect of BBP on rumen bacterial community structure. We found that the full replacement of cereal grains with BBP decreased rumen bacterial diversity, whereas the lower inclusion levels caused no changes in bacterial diversity. However, a lowered diversity does not necessarily imply a negative effect on the cow. Shabat et al. (2016) revealed that a lower richness of the rumen microbiome was tightly linked to higher feed efficiency, stating the hypothesis that lowered diversity may result in improved bacterial efficiency due to reduced competition for substrates.

The main effects on the bacterial community were an increase in Prevotella, Roseburia, and Megasphaera when $\mathrm{BBP}$ was included in the diet, mirroring the different substrate availability and improved starch digestibility of the BBP. The increased abundance of Prevotella likely explains the increased proportion of propionate in the diets containing $\mathrm{BBP}$, as this versatile genus is a major propionate producer (Mickdam et al., 2017). An increase in Prevotella is typically observed when cows are fed increasing concentrate levels, such as during the transition from low- to high-concentrate diets, as they are amylolytic and thereby thrive on starch, but also due to their ability to grow under low $\mathrm{pH}$ conditions (Purushe et al., 2010). Due to the higher digestibility of starch in the BBP as well as the decrease in $\mathrm{pH}$, the increasing effect on Prevotella was expected and this is supported by the negative correlation between several OTU belonging to the genus Prevotella and the $\mathrm{pH}$. Also the increase in Megasphaera was expected, as this bacteria is a major soluble sugar fermenter and also well known to be boosted by feeding diets high in digestible starch (Pitta et al., 2014), due to their ability to convert the lactic acid that is produced by ruminal bacteria to acetic acid and propionic acid, thereby being able to attenuate lactic acidosis (Henning et al., 2010). Interestingly, a strong increase in Roseburia was found. Overall, Roseburia is able to use starch and a dominant role of this group of bacteria in the formation of butyrate has been reported (Louis et al., 2007; Lee, 2013), and is supported by the positive correlation with starch disappearance $(\mathrm{r}=0.38, P=$ $0.02)$ and butyrate $(\mathrm{r}=0.43, P=0.01)$ production. However, other bacteria that are also able to produce butyrate, such as Butyrivibrio, decreased with the BBP inclusion. Overall, the $28 \%$ decrease in the abundance of the genus Butyrivibrio with the BBP inclusion, is likely derived from the lower availability of fiber or the increased content of EE in these diets (or both), as this genus is considered a major fibrolytic rumen microorganism (Derakhshani et al., 2017). This might be one reason for the unchanged butyrate concentration, as even an enhanced molar proportion in the BBP groups could have been expected, due to their higher amounts of sugars (Oba, 2011). Also, the decrease of some OTU belonging to the family of Ruminococcaceae pinpoints the negative effect of the BBP on fibrolytic bacteria, which is further supported by the decreased proportion of acetate, the main fermentation product of these taxa (Esquivel-Elizondo et al., 2017). Indeed, the lowest acetate proportion was found in the $45 \%$ BBP diet, which went along with the lowest NDF disappearance measured in the respective group. Also, several OTU belonging to the order of Bacteroidales were decreased in the BBP diets. In general, the order of Bacteroidales comprises amylolytic as well as cellulolytic taxa with diverse metabolic capacities (van Houtert, 1993; Henderson et al., 2015). It seems that several OTU of this order that were decreased by the BBP belong to fibrolytic bacteria, as supported by the positive association with the ruminal $\mathrm{pH}$ found especially for OTU belonging to the order of Bacteroidales, whereas these OTU 
were negatively associated with the disappearance of starch. Also, several OTU belonging to the family of Ruminococcaceae showed a positive association with the ruminal $\mathrm{pH}$, thereby supporting the general knowledge that especially fibrolytic microorganisms are sensitive to low $\mathrm{pH}$ values (Russell and Wilson, 1996). The decreased abundance of fibrolytic bacteria with the BBP inclusion might be related to the high fat content and higher concentration of UFA of the BBP, as especially elevated contents of UFA, such as oleic acid, have negative effects on microbial growth of fibrolytic bacteria in particular (Enjalbert et al., 2017).

Furthermore, this study also showed that the proportions of unclassified Clostridiales were enhanced in the BBP groups, which is consistent with previous reports that the bacterial populations in cattle fed high-grain diets contained more species belonging to the unclassified Clostridiaceae (Fernando et al., 2010; Mao et al., 2013). Therefore, these taxa likely play a significant role in the digestion of high-concentrate diets.

\section{CONCLUSIONS}

Replacing typical grains with BBP increased starch degradation and propionate proportion showing a potential for increased gluconeogenesis in cattle. However, feeding of $45 \%$ BBP resulted in decreased fiber degradation and diversity of microbes and therefore seems less recommendable in cattle diets. Further in vivo research is needed to validate our findings and to clarify the effects of the inclusion of BBP on animal health, productivity and product quality.

\section{ACKNOWLEDGMENTS}

We thank A. Dockner, S. Leiner, A. Sener, S. Sharma, and M. Wild (Institute of Animal Nutrition and Functional Plant Compounds, Vetmeduni Vienna) for their assistance with laboratory analyses and experimental material preparation. The authors acknowledge I. Kröger (Institute of Animal Nutrition and Functional Plant Compounds, Vetmeduni Vienna) for her help and technical assistance with the Rusitec trial. The authors are very grateful to the Institute of Animal Nutrition, Livestock Products and Nutrition Physiology, University of Natural Resources and Life Sciences Vienna, especially to A. Busch-Petersen, for the analysis of the fatty acid profile of the feeds. The bakery by-product was provided by Königshofer Futtermittel, Königshofer GmbH, Ebergassing, Austria. S. Aditya thanks the Austrian Agency for International Cooperation in Education and Research (ASEA UNINET, Vienna) for the $\mathrm{PhD}$ program financial support in Austria. We gratefully acknowledge the Viennese Chamber of Commerce for the support of this research (Wirtschaftskammerpreis 2016).

\section{REFERENCES}

Afzalzadeh, A., A. Boorboor, H. Fazaeli, N. Kashan, and D. Ghandi. 2007. Effect of feeding bakery waste on sheep performance and the carcass fat quality. J. Anim. Vet. Adv. 6:559-562.

Arosemena, A., E. DePeters, and J. Fadel. 1995. Extent of variability in nutrient composition within selected by-product feedstuffs. Anim. Feed Sci. Technol. 54:103-120.

Bokulich, N. A., S. Subramanian, J. J. Faith, D. Gevers, J. I. Gordon, R. Knight, D. A. Mills, and J. G. Caporaso. 2013. Quality-filtering vastly improves diversity estimates from Illumina amplicon sequencing. Nat. Methods 10:57-59.

Caporaso, J. G., J. Kuczynski, J. Stombaugh, K. Bittinger, F. D. Bushman, E. K. Costello, N. Fierer, A. G. Pena, J. K. Goodrich, J. I. Gordon, G. A. Huttley, S. T. Kelley, D. Knights, J. E. Koening, R. E. Ley, C. A. Lozupone, D. McDonald, B. D. Muegge, M. Pirrung, J. Reeder, J. R. Sevinsky, P. T. Turnbaugh, W. A. Walters, J. Widman, T. Yatsunenko, J. Zaneveld, and R. Knight. 2010. QIIME allows analysis of high-throughput community sequencing data. Nat. Methods 7:335-336.

Champe, K. A., and D. C. Church. 1980. Digestibility of dried bakery product by sheep. J. Anim. Sci. 51:25-27.

Deckardt, K., A. Khol-Parisini, and Q. Zebeli. 2013. Peculiarities of enhancing resistant starch in ruminants using chemical methods: Opportunities and challenges. Nutrients 5:1970-1988.

Derakhshani, H., H. M. Tun, F. C. Cardoso, J. C. Plaizier, E. Khafipour, and J. J. Loor. 2017. Linking peripartal dynamics of ruminal microbiota to dietary changes and production parameters. Front. Microbiol. 7:2143. https://doi.org/10.3389/fmicb.2016.02143.

Edgar, R. C. 2010. Search and clustering orders of magnitude faster than BLAST. Bioinformatics 26:2460-2461.

Enjalbert, F., S. Combes, A. Zened, and A. Meynadier. 2017. Rumen microbiota and dietary fat: A mutual shaping. J. Appl. Microbiol. 123:782-797

Esquivel-Elizondo, S., Z. E. Ilhan, E. Garcia-Peña, and R. KrajmalnikBrown. 2017. Insights into butyrate production in a controlled fermentation system via gene predictions. mSystems 2:eccc51-17.

Federal Ministry of Health. 2004. Verordnung der Bundesministerin für Gesundheit und Frauen über die Mindestanforderungen für die Haltung von Pferden und Pferdeartigen, Schweinen, Rindern, Schafen, Ziegen, Schalenwild, Lamas, Kaninchen, Hausgeflügel, Straußen und Nutzfischen (1. Tierhaltungsverordnung) StF: BGBl. II Nr. 485/2004. Bundeskanzleramt Österreich, Vienna, Austria.

Fernando, S. C., H. T. Purvis, F. Z. Najar, L. O. Sukharnikov, C. R. Krehbiel, T. G. Nagaraja, B. A. Roe, and U. DeSilva. 2010. Rumen microbial population dynamics during adaptation to a highgrain diet. Appl. Environ. Microbiol. 76:7482-7490.

Franca, A. B., M. J. F. Morenz, F. C. F. Lopez, A. S. Madeiro, D A. Morenz, B. M. de Faria, L. D. Silva Cabral, and C. E. M. da Fonseca. 2012. Bakery waste in sheep diets: Intake, digestibility, nitrogen balance and ruminal parameters. Rev. Bras. Zootec. 41:147-153.

Godfray, H. C. J., J. R. Beddington, I. R. Crute, L. Haddad, D. Lawrence, J. F. Muir, J. Pretty, S. Robinson, S. M. Thomas, and C. Toulmin. 2010. Food security: The challenge of feeding 9 billion people. Science 327:812-818.

Haddad, S. G., and K. I. Ereifej. 2004. Substituting bread by-product for barley grain in fattening diets for Baladi kids. Asian-Australas. J. Anim. Sci. 17:629-632.

Henderson, G., F. Cox, S. Ganseh, A. Jonker, W. Young, Global Rumen Census Collaborators, and P. H. Janssen. 2015. Rumen microbial community composition varies with diet and host, but a core microbiome is found across a wide geographical range. Sci. Rep. 5:14567. 10.1038/srep14567.

Henning, P. H., C. H. Horn, D. G. Steyn, H. H. Meissner, and F. M. Hagg. 2010. The potential of Megasphaera elsdenii isolates to control ruminal acidosis. Anim. Feed Sci. Technol. 157:13-19. 
Humer, E., R. M. Petri, J. R. Aschenbach, B. J. Bradford, G. B. Penner, M. Tafaj, K.-H. Südekum, and Q. Zebeli. 2017. Invited review: Practical feeding management recommendations to mitigate the risk of subacute ruminal acidosis in dairy cattle. J. Dairy Sci. 101:872-888. https://doi.org/10.3168/jds.2017-13191.

Humer, E., and Q. Zebeli. 2017. Grains in ruminant feeding and potentials to enhance their nutritive and health value by chemical processing. Anim. Feed Sci. Technol. 226:133-151.

Hünerberg, M., S. M. McGinn, K. A. Beauchemin, E. K. Okine, O. M. Harstad, and T. A. McAlisster. 2013. Effect of dried distillers grains plus solubles on enteric methane emissions and nitrogen excretion from growing beef cattle. J. Anim. Sci. 91:2846-2857.

Jayanegara, A., G. Goel, H. P. S. Makkar, and K. Becker. 2010. Reduction in methane emissions from ruminants by plant secondary metabolites: Effects of polyphenols and saponins. Pages 151-157 in Sustainable Improvement of Animal Production and Health. N. E. Odongo, M. Garcia, and G. J. Viljoen, ed. Food and Agricultural Organization of the United Nations, Rome, Italy.

Khiaosa-Ard, R., B. U. Metzler-Zebeli, S. Ahmed, A. Muro-Reyes, K. Deckardt, R. Chizzola, J. Böhm, and Q. Zebeli. 2015. Fortification of dried distillers grains plus soluble with grape seed meal in the diet modulates methane mitigation and rumen microbiota in Rusitec. J. Dairy Sci. 98:2611-2626.

Kong, Y., R. Teather, and R. Forster. 2010. Composition, spatial distribution, and diversity of the bacterial communities in the rumen of cows fed different forages. FEMS Microbiol. Ecol. 74:612-622.

Lee, Y. K. 2013. Effects of diet on gut microbiota profile and the implications for health and disease. Biosci. Microbiota Food Health 32:1-12.

Louis, P., K. P. Scott, S. H. Duncan, and H. J. Flint. 2007. Understanding the effects of diet on bacterial metabolism in the large intestine. J. Appl. Microbiol. 102:1197-1208.

Mao, S. Y., R. Y. Zhang, D. S. Wang, and W. Y. Zhu. 2013. Impact of subacute ruminal acidosis (SARA) adaptation on rumen microbiota in dairy cattle using pyrosequencing. Anaerobe 24:12-19.

Mickdam, E., R. Khiaosa-Ard, B. U. Metzler-Zebeli, E. Humer, H. Harder, A. Khol-Parisini, and Q. Zebeli. 2017. Modulation of ruminal fermentation profile and microbial abundance in cows fed diets treated with lactic acid, without or with inorganic phosphorus supplementation. Anim. Feed Sci. Technol. 230:1-12.

Oba, M. 2011. Review: Effects of feeding sugars on productivity of lactating dairy cows. Can. J. Anim. Sci. 91:37-46.

Obeidat, B. S., S. G. Haddad, H. H. Titi, M. A. Abu Ishmais, and B. T. Telfah. 2012. Performance of nursing awassi ewes fed different levels of bread by-product. Asian-australas. J. Anim. Sci. 25:1132-1137.

Peterson, J., S. Garges, M. Giovanni, P. McInnes, L. Wang, J. Schloss, V. Bonazzi, J. McEwen, K. Wetterstrand, C. Deal, C. Baker, V. Di Francesco, T. Howcroft, R. Karp, R. Lunsford, C. Wellington, T. Belachew, M. Wright, C. Giblin, H. M. David, and M. Guyer. 2009. The NIH Human Microbiome Project. Genome Res. 19:2317-2323.

Pitta, D. W., S. Kumar, B. Vecchiarelli, D. J. Shirely, K. Bittinger, L. D. Baker, J. D. Ferguson, and N. Thomsen. 2014. Temporal dynamics in the ruminal microbiome of dairy cows during the transition period. J. Anim. Sci. 92:4014-4022.

Purushe, J., D. E. Fouts, M. Morrison, B. A. White, R. I. Mackie, P. M. Coutinho, B. Henrissat, and K. F. Nelson. 2010. Comparative genome analysis of Prevotella ruminicola and Prevotella bryantii: Insights into their environmental niche. Microb. Ecol. 60:721-729.
Quast, C., E. Pruesse, P. Yilmaz, J. Gerken, T. Schweer, P. Yarza, J. Peplies, and F. O. Glockner. 2013. The SILVA ribosomal RNA gene database project: Improved data processing and web-based tools. Nucleic Acids Res. 41:D590-D596.

Qumar, M., R. Khiaosa-Ard, P. Pourazad, S. U. Wetzels, F. Klevenhusen, W. Kandler, J. R. Aschenbach, and Q. Zebeli. 2016. Absorption from the reticulorumen of non-lactating cattle fed high concentrate diets. PLoS One 11:e164192.

Russell, J. B., and D. B. Wilson. 1996. Why are ruminal cellulolytic bacteria unable to digest cellulose at low pH? J. Dairy Sci. 79:1503-1509

Shabat, S. K., G. Sasson, A. Doron-Faigenboim, T. Durman, S. Yaacoby, M. E. Berg Miller, B. A. White, N. Shterzer, and I. Mizrahi. 2016. Specific microbiome-dependent mechanisms underlie the energy harvest efficiency of ruminants. ISME J. 10:2958-2972.

Soliva, C. R., and H. D. Hess. 2007. Measuring methane emission of ruminants by in vitro and in vivo techniques. Pages 13-15 in Measuring Methane Production from Ruminants. H. P. S. Makkar and P. E. Vercoe, ed. Springer, Dordrecht, the Netherlands.

Suen, G., D. M. Stevenson, D. C. Bruce, O. Chertkov, A. Copeland, J.-F. Cheng, C. Detter, J. C. Detter, L. A. Goodwin, C. S. Han, L. J. Hauser, N. N. Ivanova, N. C. Kyrpides, M. L. Land, A. Lapidus, S. Lucas, G. Ochinnikova, S. P. Pitluck, R. Tapia, T. Woyke, J. Boyum, D. Mead, and P. Weimer. 2011a. Complete genome of the cellulolytic ruminal bacterium Ruminococcus albus. J. Bacteriol. 193:5574-5575.

Suen, G., P. J. Weimer, D. M. Stevenson, F. O. Aylward, J. Boyum, J. Deneke, C. Drinkwater, N. Ivanova, N. Mikhailova, O. Chertkov, L. A. Goodwin, C. R. Curie, D. Mead, and P. J. Brumm. 2011b. The complete genome sequence of Fibrobacter succinogenes S85 reveals a cellulolytic and metabolic specialist. PLoS One 6:e18814. https://doi.org/10.1371/journal.pone.0018814.

Sukhija, P. S., and D. L. Palmquist. 1988. Rapid method for determination of total fatty acid content and composition of feedstuffs and feces. J. Agric. Food Chem. 36:1202-1206.

van Houtert, M. F. J. 1993. The production and metabolism of volatile fatty acids by ruminants fed roughages: A review. Anim. Feed Sci. Technol. 43:189-225.

Van Soest, P. J., J. B. Robertson, and B. A. Lewis. 1991. Methods for dietary fiber, neutral detergent fiber, and nonstarch polysaccharides in relation to animal nutrition. J. Dairy Sci. 74:3583-3597.

VDLUFA (Association of German Agricultural Analytic and Research Institutes). 2012. Die Chemische Untersuchung von Futtermitteln. 8. Erg. 2012. VDLUFA-Verlag, Darmstadt, Germany.

Wallace, R. J. 1994. Amino acid and protein synthesis, turnover and breakdown by ruminal microorganisms. Pages 71-112 in Principles of Protein Nutrition of Ruminants. J. M. Asplund, ed. CRC Press, Boca Raton, FL.

Weatherburn, M. W. 1967. Phenol-hypochlorite reaction for determination of ammonia. Anal. Chem. 39:971-974.

Wing, J. M. 1964. Preliminary evaluation of dried bakery product in dairy cattle rations. Pages $1-5$ in Dairy Sci. Mimeo Report 64-2 Apr. 28, Florida Agric. Exp. Sta., Gainesville.

Yilmaz, P., L. W. Parfrey, P. Yarza, J. Gerken, E. Pruesse, C. Quast, T. Schweer, J. Peplies, W. Ludwig, and F. O. Glockner. 2014. The SILVA and "All-species Living Tree Project (LTP)" taxonomic frameworks. Nucleic Acids Res. 42:D643-D648.

Zhang, Z., S. Schwartz, L. Wagner, and W. Miller. 2000. A greedy algorithm for aligning DNA sequences. J. Comput. Biol. 7:203-214. 